\title{
Methods of a multisite randomized clinical trial of supported employment among veterans with spinal cord injury
}

\begin{abstract}
Lisa Ottomanelli, PhD; ${ }^{1 *}$ Lance Goetz, MD; ${ }^{1}$ Charles McGeough, MS; ${ }^{2}$ Alina Suris, PhD; ${ }^{3} \mathrm{Jennifer} \mathrm{Sippel,} \mathrm{PhD;}^{1}$ Patricia Sinnott, PT, PhD, MPH; ${ }^{4-5}$ Todd H. Wagner, PhD; ${ }^{6}$ Daisha J. Cipher, PhD $^{7}$

${ }^{1}$ Department of Veterans Affairs (VA) North Texas Health Care System, Department of Physical Medicine and Rehabilitation, University of Texas Southwestern Medical School, Dallas, TX; ${ }^{2}$ VA Central Office, Office of Mental Health, Psychosocial Rehabilitation and Recovery Therapeutic and Supported Employment Services, Washington, DC; ${ }^{3}$ VA North Texas Health Care System, Department of Psychiatry, University of Texas Southwestern Medical School, Dallas, TX; ${ }^{4}$ VA Health Economics Resource Center (HERC), Center for Primary Care Outcomes and Research and Center for Health Policy, Stanford University, Stanford CA; ${ }^{5}$ Department of Physical Therapy and Rehabilitation Science, University of California San Francisco, San Francisco, CA; ${ }^{6}$ VA HERC, Health Research and Policy, Stanford University School of Medicine, Stanford, CA; ${ }^{7}$ VA North Texas Health Care System, School of Nursing, University of Texas at Arlington, Arlington, TX
\end{abstract}

\begin{abstract}
This article compares the methods of a randomized multisite clinical trial of evidence-based supported employment with conventional vocational rehabilitation among veterans with spinal cord injury (SCI). The primary hypothesis is that, compared with conventional vocational rehabilitation (i.e., standard care), evidence-based supported employment will significantly improve competitive employment outcomes and general rehabilitation outcomes. The secondary hypothesis is that evidencebased supported employment in SCI will be more cost-effective than standard care. The current article describes the clinical trial and presents baseline data. The present sample includes 301 veterans with SCI, which includes paraplegia (50\%), high tetraplegia (32\%), and low tetraplegia (18\%). Baseline data indicate that $65 \%$ of this sample of employment-seeking veterans with SCI had never been employed postinjury, despite the fact that nearly half (41\%) had received some type of prior vocational rehabilitation. These rates of unemployment for veterans with SCI are consistent with the rates reported for community samples of persons with SCI. Forthcoming outcome data will provide much needed insights into the best practices for helping these veterans restore vocational goals and improve overall quality of life.
\end{abstract}

Clinical Trial Registration: NCT00117806, “A spinal cord injury vocational integration program: Implementation and outcomes"; http://clinicaltrials.gov/ct2/show/NCT00117806/.
Key words: Department of Veterans Affairs, employment, evidence-based practice, multicenter trial, persons with disabilities, randomized controlled trial, rehabilitation, research design, spinal cord injuries, supported employment.

Abbreviations: $\mathrm{CEA}=$ cost-effectiveness analysis, $\mathrm{CHART}=$ Craig Handicap Assessment and Reporting Technique, CPRS = Computerized Patient Record System, CWT = compensated work therapy, FIM = Functional Independence Measure, ICER = incremental cost-effectiveness ratio, IRB = institutional review board, MANCOVA = multivariate analysis of covariance, $\mathrm{OR}=$ odds ratio, PI = principal investigator, QALY = quality-adjusted lifeyears, SCI = spinal cord injury, SCI-VIP $=$ Spinal Cord Injury Vocational Integration Program, SE = supported employment, SGA = substantial gainful activity, SMI = serious mental illness, VA = Department of Veterans Affairs, VAMC = VA medical center, VBA = Veterans Benefits Administration, VHA = Veterans Health Administration, VR-36 = Veterans RAND 36-Item Health Survey, $\mathrm{VRC}=$ vocational rehabilitation counselor, VR\&E = Vocational Rehabilitation and Employment.

* Address all correspondence to Lisa Ottomanelli, PhD; VA North Texas Health Care System-Spinal Cord Injury Center, 4500 S Lancaster Road (128), Dallas, TX 75216; 214-8571768; fax: 214-857-1759. Email: lisa.ottomanelli@va.gov DOI:10.1682/JRRD.2008.10.0145 


\section{INTRODUCTION}

Unemployment is a serious and prevalent problem among persons with spinal cord injury (SCI) and is associated with reduced life expectancy and significant declines in quality of life [1-3]. Among persons with SCI, 13 to 69 percent are unemployed [4] and the unemployment rate is more than tenfold greater than the general unemployment rate. People with SCI who regain employment report greater life satisfaction, quality of life, and adjustment than those who remain unemployed [1,5-7]. Although employment has historically been a hallmark of effective rehabilitation, little is known about the approaches that best help people with SCI return to work.

The Veterans Health Administration (VHA) operates the largest and most comprehensive network of SCI care in the nation. The SCI centers provide a variety of services, but there is presently no evidence-based or systematic method of addressing vocational rehabilitation needs of veterans with SCI in VHA. In most cases, vocational rehabilitation is available through referrals outside the SCI centers. For example, all veterans with SCI are eligible for state vocational rehabilitation and a portion of veterans who have eligible military service-connected disabilities can be served by the Veterans Benefits Administration (VBA) Vocational Rehabilitation and Employment (VR\&E) department.

Evidence-based supported employment (SE) is a vocational rehabilitation modality that uses an integrated approach to help people obtain and maintain communitybased competitive employment in their chosen occupation [8-10]. Evidence-based SE has successfully assisted persons with serious mental and intellectual disabilities in both the general and veteran populations. Bond et al. recently reviewed randomized controlled trials of high fidelity SE [11]. They concluded that evidence-based SE is one of the most robust interventions available for persons with serious mental illness (SMI). In 2004, the VHA implemented a large-scale initiative to provide SE to veterans with SMI under the auspices of the Mental Health Compensated Work Therapy (CWT) Programs [12]. To date, the SE model has not been widely used or clinically tested among persons with physical disabilities, such as SCI. While some modifications may be necessary, this model holds great promise as an effective approach to vocational rehabilitation for veterans with physical disabilities as well.

The present article describes the introduction and investigation of effective methods of meeting the vocational rehabilitation needs of veterans with SCI through a multicenter randomized clinical trial. The trial described in this article will test whether evidence-based SE meets the vocational rehabilitation needs of veterans with SCI more effectively than standard care (referrals to conventional vocational rehabilitation). Additionally, the study will determine the cost-effectiveness and budget impact of the program should it be adopted.

\section{METHODS}

This study is a prospective, multisite randomized control trial of SE versus standard vocational rehabilitation care in a population of veterans with SCI treated at various Department of Veterans Affairs (VA) medical center (VAMC) SCI centers. The study examines the occupational outcomes as assessed by measures of competitive employment and psychosocial functioning. Each participating site obtained approval from its respective institutional review board (IRB).

\section{Intervention}

\section{Spinal Cord Injury Vocational Integration Program}

The Spinal Cord Injury Vocational Integration Program (SCI-VIP) is built on the principles of evidencebased SE as applied in an SCI medical rehabilitation setting. The program integrates vocational services into the SCI continuum of healthcare by collaboratively building a pathway that uses existing resources, namely the expertise of both the SCI healthcare team and the CWT SE team, to address the ongoing vocational needs of veterans with SCI. In this model, a vocational rehabilitation counselor (VRC), who is trained in SE practices, is an integral member of the existing interdisciplinary SCI treatment team and thereby has access to and is able to utilize the treatment team's resources to enhance vocational rehabilitation services. In the SCI-VIP condition, the VRC is responsible for integrating and coordinating vocational rehabilitation services.

The SCI-VIP is based on the following evidencebased SE principles [10,13]:

1. Integrated treatment. Vocational rehabilitation is considered an integral component of interdisciplinary SCI care rather than a separate service.

2. Rapid engagement. Emphasis is on immediate assistance with job finding rather then lengthy prevocational assessment or training. 
3. Competitive employment. The goal is paid jobs in regular work settings; that is, jobs that anyone can obtain regardless of disability status.

4. Belief that success is possible regardless of severity or type of disability. People with severe disabilities can directly obtain and succeed in competitive jobs.

5. Ongoing support. Follow-along supports continue for a time that fits the individual rather than terminating at a set point after a job is started.

6. Veteran preferences. Job finding and job supports are based on clients' preferences and choices rather than on providers' judgments.

7. Community-based services. Services are primarily provided in the community, rather than in mental health treatment or rehabilitation settings.

8. Personalized benefits counseling. Veterans with disabilities considering employment need up-to-date information from qualified disability benefits counselors.

\section{SCI-VIP Clinician Training}

Initial Hiring and Training. Before enrollment, investigators spent 4 to 6 months recruiting and hiring VRCs to provide the new evidence-based SE services at selected VAMCs. All VRCs have master's degrees and are certified rehabilitation counselors. The original training consisted of a 3-day workshop taught by VA faculty who were coinvestigators on the project and experts in the clinical care of patients with SCI and by outside national consultants who had expertise in evidenced-based SE with individuals with serious mental and intellectual disabilities. The training was comprehensive, covering both issues specific to management and care of patients with SCI and evidence-based SE practices. The training in its entirety is described elsewhere [14].

Ongoing Training and Supervision. VRCs receive ongoing instruction and coaching by a coinvestigator who has more than 30 years of experience in vocational rehabilitation and is centrally involved with the VA Supportive Employment initiative for the Seriously Mentally Ill and by a national management consultant in SE from the University of Georgia School of Public Health. This ongoing coaching in evidence-based SE occurs via monthly conference calls, and technical assistance is also provided during biannual fidelity review visits (subsequently described in detail). The VRCs are directly supervised at the local level by experienced vocational rehabilitation clinicians who are program managers in the VA Mental Health CWT Programs and who are either licensed psychologists or social workers.

\section{Standard Care}

Typically, veterans with SCI who are interested in employment are referred outside the VA SCI centers to providers who are not members of the SCI healthcare team and who may not have knowledge of or experience with the unique issues relevant to veterans with SCI. For example, all veterans, regardless of disability benefits status, can be referred to state vocational rehabilitation services. Eligible veterans who receive military service-connected benefits can be referred to VBA VR\&E services. The services they receive through these providers are conventional vocational rehabilitation services that typically use a case management approach. These vocational rehabilitation services vary widely in nature and intensity from state to state and may include referrals to training programs, jobplacement services, and rehabilitation technology assistance. Because caseworkers in state agencies and VR\&E carry a caseload that far surpasses the caseload requirement associated with SE, study subjects in the standardcare condition will not receive a vocational rehabilitation approach that resembles our SE treatment condition [15]. Subjects in the standard-care condition carry the burden of accessing and coordinating available vocational rehabilitation services themselves. Our current data indicate that $<9$ percent of control subjects have had one or more visits to a vocational rehabilitation provider. For those 9 percent who sought vocational assistance, none of the facilities was providing a service that resembled SE.

\section{Design}

\section{Hypotheses}

The study examines whether, compared with standard care, evidence-based SE integrated into SCI rehabilitation and sustaining healthcare (SCI-VIP) will result in significantly improved employment and psychosocial outcomes. Our hypotheses are-

1. Evidence-based SE will improve competitive employment outcomes and general rehabilitation outcomes significantly more than conventional vocational rehabilitation (i.e., standard care) among veterans with SCI.

2. SCI-VIP will be cost-effective compared to standard care.

\section{Study Design and Sampling Approach}

The study design is a randomized clinical trial consisting of an experimental group and a comparison group (Figure). The experimental group is referred to as the "SCI-VIP condition" and consists of veterans who receive 
evidence-based SE within the SCI center. The comparison group is referred to as the "standard-care condition" and consists of veterans who are referred for vocational rehabilitation services outside the SCI centers per their usual practice. The target population for this study consists of veterans receiving rehabilitation or sustaining care from interdisciplinary care teams in the SCI centers at participating VAMCs. Participating VAMCs are located in the following U.S. cities: Chicago, Cleveland, Dallas, Houston, Milwaukee, San Diego, and St. Louis. A wide variety of factors were considered in the selection of study sites, such as location in a metropolitan geographical region, adequate economic and industrial development, strong management and leadership support at the local medical center, available subject pool, and existing public transportation systems.

The VAMCs where the SCI-VIP is implemented are referred to as the "interventional sites." Interventionalsite subjects were randomized to either the experimental group or the comparison group. The VAMCs where the SCI-VIP is not implemented are referred to as the "observational sites.” The observational sites were selected based on similarity to the interventional site facilities with regard to subjects, communities, and VAMC culture. All observational-site subjects were enrolled into a comparison group. These observational sites are included because of the assumption that veterans and staff at the four interventional facilities might be vicariously influenced by veterans and staff involved with SCI-VIP implementation. Using the observational (nonrandomized) comparison subjects for all data collection is expected to strengthen comparisons between the outcomes for subjects in the experimental and comparison groups.

Inclusion criteria for the study were (1) age between 18 and 64 years; (2) SCI as a result of trauma or disease; (3) medical and neurological stability as determined by the principal investigator (PI), who was a physician or psychologist (at one site) at the SCI Center; when necessary, the local PI would consult with the patient's attending SCI physician to determine this; (4) residence within the metropolitan area proximal to the VAMC; (5) access to transportation; (6) interest in competitive employment as an outcome of participation; and (7) willingness to sign the consent form indicating voluntary and informed consent. Exclusion criteria were (1) medical and/or surgical instability, (2) mental impairment such that independent reasoning and judgment jeopardize safety of self and others, (3) active alcohol and/or drug dependency that is untreated, (4) competitive employment and earnings higher than the Social
Security Administration's annual determination of substantial gainful activity (SGA) at the time of recruitment, and (5) unwillingness to complete the consenting process.

\section{Procedures}

Potential participants are referred by SCI treatment providers or self-refer after reading IRB-approved study advertising materials. The site coordinator at the participating VAMC meets with each referral to review the study and obtain informed consent. Subjects drawn from the interventional sites who meet inclusion criteria are randomized to either the experimental group or the comparison group. Veterans who receive healthcare from the observational sites and meet inclusion criteria are not randomized but asked to participate as comparison-group subjects (Figure).

All subjects are followed for 12 months, during which time face-to-face interviews every 3 months are conducted to collect data on both primary employment

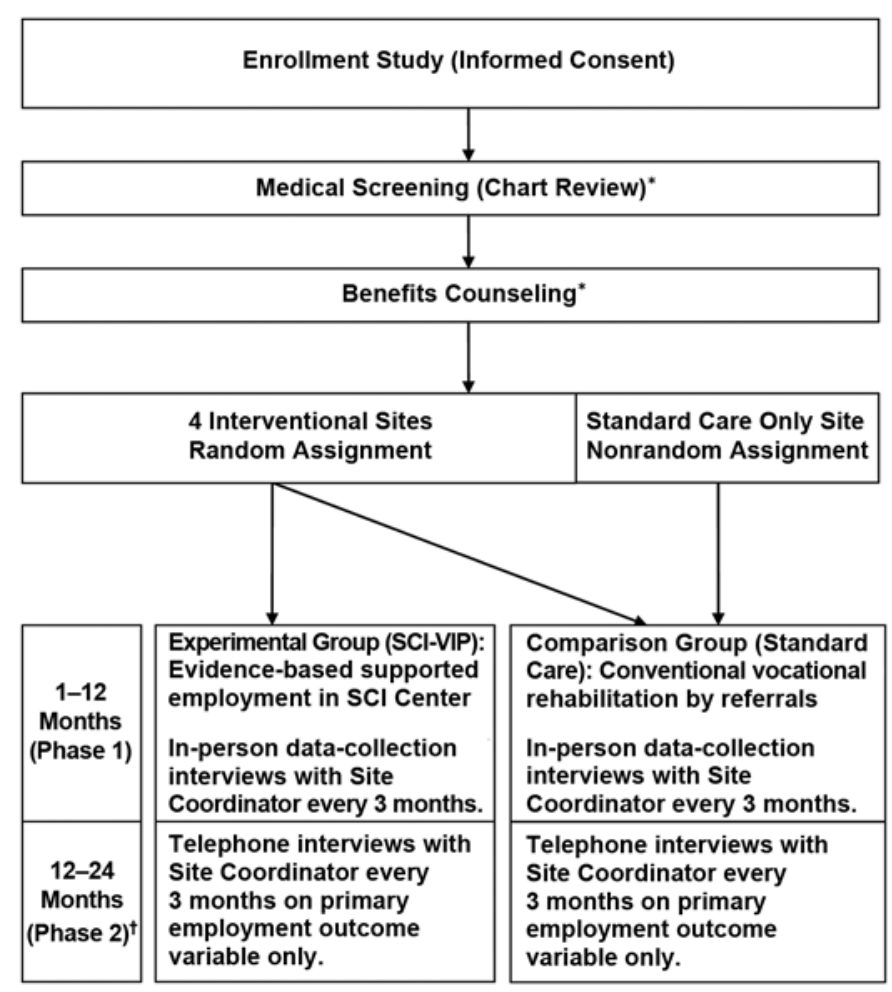

Figure.

Study design for Spinal Cord Injury (SCI) Vocational Integration Program (SCI-VIP), a multisite randomized clinical trial of supported employment among veterans with SCI. ${ }^{*}$ These processes may occur simultaneously. ${ }^{\dagger}$ Twelve months of follow-up data will be available for the percentage of sample enrolled before $4 / 1 / 09$, whereas twenty-four months of data will be available for those enrolled before $4 / 1 / 08$. 
variables and secondary outcomes measures (phase 1 ). On February 2008, the follow-up period was extended to 24 months at all sites, allowing telephone interviews to be conducted every 3 months during months 12 to 24 on the primary employment outcome measure (phase 2) for the remaining sample.

\section{Benefits Counseling}

All participants are referred for benefits counseling upon enrolling in the study. Social Security benefits information is available through local Work Incentive Planning and Assistance projects, and veterans benefits information is made available through Paralyzed Veterans of America National Service Officers at the local VAMC SCI centers. These referrals allow participants the opportunity to learn about their current benefits, understand the role of work incentives and protections of disability benefits, and evaluate the impact that employment could have on their disability benefits. Veterans are notified that their VA benefits are protected while participating in CWT SE.

\section{Randomization and Sample Size}

To guarantee a certain number of subjects in the experimental group at each interventional site, we conducted randomization using a biased coin design. Biased coin designs are used when researchers need to balance the number of subjects in each treatment condition-which is often not achieved with conventional coin designs. This form of randomization ensures that a certain minimum number of subjects gets randomized to the treatment condition [16]. In this study, two randomization protocols are applied, each of which depends on the number of active participants. The experimental-group loading is used when less than eight active participants are in the experimental group at a study site. Specifically, experimental subjects are randomized with a 0.8 probability of being randomized to the experimental group and a 0.2 probability of being randomized to the comparison group. The comparison-group loading is used when more than eight active participants are in the experimental group at a study site. Comparison subjects recruited are randomized with a 0.2 probability of being randomized to the experimental group and a 0.8 probability of being randomized to the comparison group.

Power analyses indicated that 126 subjects will be required to complete the study to address our primary research objective using logistic regression analysis of our primary study outcome: employment. Existing literature predicts that 15 percent of our comparison group and 40 percent of our experimental group would be likely to significantly improve in return to work. Thus, our power analysis was based on a moderate anticipated effect size (odds ratio $[\mathrm{OR}]=2.5$ ), a study alpha of 0.05 , and a beta of 0.20 . Our secondary outcome variables will be analyzed using multivariate analyses of variance and will require 196 subjects. To accommodate for potential attrition, we will enroll 240 subjects, 40 percent of whom $(n=96)$ will be experimental subjects and 60 percent $(n=144)$ comparison subjects.

After each subject completes the baseline interview, the local research coordinators from interventional sites contact the coordinating center at the Dallas VAMC and then the random assignment is determined. Because of the obvious differences between the experimental-group and comparison-group procedures, blinding of staff or subjects is not possible. A Data Safety Monitoring Board convenes annually with the project investigators and biostatistician to provide a critical and unbiased evaluation of the study's progress, including patient enrollment and safety, protocol deviations, efficacy of randomization, adverse events, and treatment efficacy.

\section{Statistical Analysis Plan}

All study variables will be descriptively analyzed for measures of central tendencies and variance between subjects in the experimental versus comparison groups as well as between subjects in each study group drawn from each VAMC. Traditional parametric and nonparametric statistical approaches will be used to identify differences between the experimental and comparison groups on demographics and all outcome study variables. The following sections detail our approach to the analyses of each part of our hypotheses.

Primary Hypothesis. Evidence-based SE will improve competitive employment outcomes and general rehabilitation outcomes (health and quality of life) significantly more than conventional vocational rehabilitation (i.e., standard care) among veterans with SCI. Analyses of employment success will employ multivariate logistic regression. We will examine the extent to which patients in the SCI-VIP group achieve significantly more employment success than those in the comparison group by computing unadjusted ORs followed by adjusted ORs, with employment status as the dependent variable, treatment group as the predictor, and covariates including study site, demographic variables, and 
baseline employment status. Analyses of our continuous outcome variables (employment index, perceived barriers to employment, level of handicap, quality of life, depression, and sustaining care needs) will employ mixed factorial multivariate analyses of covariance (MANCOVAs) to determine treatment group differences over time on the outcome variables, controlling for specified covariates. In the event that the distributions of the outcome variables are nonnormal, appropriate transformations will be applied to render them suitable for multivariate analyses [17] and sphericitycorrected multivariate indexes will be computed if necessary. The "between" factor is treatment group (SCI-VIP vs comparison) and the "within" factor is time of assessment (baseline, month 3, month 6, month 9, and month 12). Covariates will include study site, sex, and age. We will compute eta-squared values to represent effect sizes of each of the MANCOVA results to determine the magnitude of variance explained in the outcomes by the factors, along with adjusted mean differences with 95 percent confidence intervals.

Secondary Hypothesis. SCI-VIP will be cost-effective compared to standard care. Because policymakers have financial questions that will not be answered by the costeffectiveness analysis (CEA), we will undertake a budget-impact analysis. As its name implies, this analysis is similar to the CEA but considers the purchaser perspective (i.e., the VA) within a short time frame (1 to 2 years). The health economic analysis of the SCI-VIP program will analyze the immediate impact of the intervention on costs and quality of life during the first 12 months from randomization. If the intervention is not effective or the intervention is both more effective and less costly (known as dominance), the economic analysis will have reached a clear conclusion. If, as expected, the intervention is both more effective and more costly than standard care, we will estimate the cost-effectiveness of the SCIVIP program compared with that of standard care. If the SCI-VIP program is determined to be cost-effective, we will undertake a budget-impact analysis to estimate the costs to VA of adopting the new program.

The CEA of the SCI-VIP program compared with that of standard care will follow widely accepted and recommended methods [18-19], including the use of the societal perspective. This analysis will include the costs for healthcare services and caregiver and patient-incurred costs. Outcomes will be expressed in quality-adjusted life-years (QALYs). We will estimate the quality adjustment by using the Short Form-6D utility weights, extrap- olated from the Veterans RAND 36-item Health Survey (VR-36) survey scores, which will be periodically measured during the trial [20-21]. We will estimate the incremental cost-effectiveness ratio (ICER) for the SCI-VIP program compared with standard care as

$$
\operatorname{ICER}=\frac{C_{2}-C_{1}}{Q_{2}-Q_{1}},
$$

where $C_{2}$ represents the cost of the study intervention, $C_{1}$ the costs of standard care, $Q_{2}$ the QALYs gained with the SCI-VIP program, and $Q_{1}$ the QALYs gained with the standard-care intervention. The results will be reported as cost per QALY gained. Stochastic analysis will be undertaken with the use of cost-effectiveness acceptability curves to express uncertainty around cost-effectiveness ratios based on mean costs and outcomes [19].

We will estimate costs of the intervention, healthcare utilization, patient travel time, and caregiver time. VA cost and utilization data will be gathered from centralized VA databases, which capture all healthcare services provided or paid for by VA for each subject. The time spent and the types of services provided by the VRCs in the intervention arm are gathered in the VA electronic health record (the Computerized Patient Record System [CPRS]) with an expanded VRC event capture screen modified for the study. Using the CPRS to enter time and services provided is routine for VA providers. The study coordinator time for quarterly face-to-face research visits or telephone calls will be excluded because these represent research costs. We will supplement the VA administrative data with self-reported non-VA healthcare utilization. We will measure travel expenses by surveying study participants at baseline about the distance they usually travel to receive medical care and then estimating travel expenses as the product of the distance traveled and the per-mile travel expense for private automobiles [22], using the rate allowed as a tax-deduction by the U.S. Internal Revenue Service. Information about the patient's caregiver will be collected on the case report forms at each study visit and will be valued with the use of the average market payment rate for home health aides performing chore services. All costs will be converted to a standardized year with use of the Consumer Price Index for all goods. 


\section{Outcomes}

\section{Rehabilitation Outcomes}

Competitive Employment. The primary outcome measure is the rate of CE among study participants. CE is defined as "community jobs that pay at least minimum wage (paid directly by the employer to the employee) that any person can apply for, including full-time and part-time jobs" [23]. Employment data are collected every 3 months and include weekly documentation of employment status, job title, wages, hours actually worked, hours missed, type of leave used (reflecting benefits such as paid vacation or sick time), and reasons for missing any work (medical or nonmedical). This employment information is similar to primary employment outcome data points obtained in other randomized clinical trials of SE [11,24-25]. The employment outcome data are supplemented with quarterly collection of job-seeking activity, volunteer hours, and academic or training course participation. The Table summarizes the SCI-VIP measures, methods, and administration time points.

Health and Quality of Life. The general rehabilitation outcome variables include the following health and quality-of-life indicators: level of handicap, health-related quality of life, use of inpatient and outpatient medical services, level of depression, and perceived barriers to employment. Medical chart reviews are conducted at baseline and 12 months and include date and level of injury and impairment level. Repeated measurement was used to account for changes in neurologic status that may occur (e.g., due to syringomyelia) or lessening of impairment that could occur with continued rehabilitation. SCI Model System categories were utilized to determine coinjuries, cause of injury, and medical and mental health comorbidities [26]. The Functional Independence Measure (FIM) is widely used with the SCI population to measure rehabilitation progress [2730]. FIM scores garnered from medical chart reviews establish severity of disability at baseline and 12 months.

Table.

Spinal Cord Injury Vocational Integration Program (SCI-VIP) measures, methods, and administration time points (shown in months unless otherwise indicated).

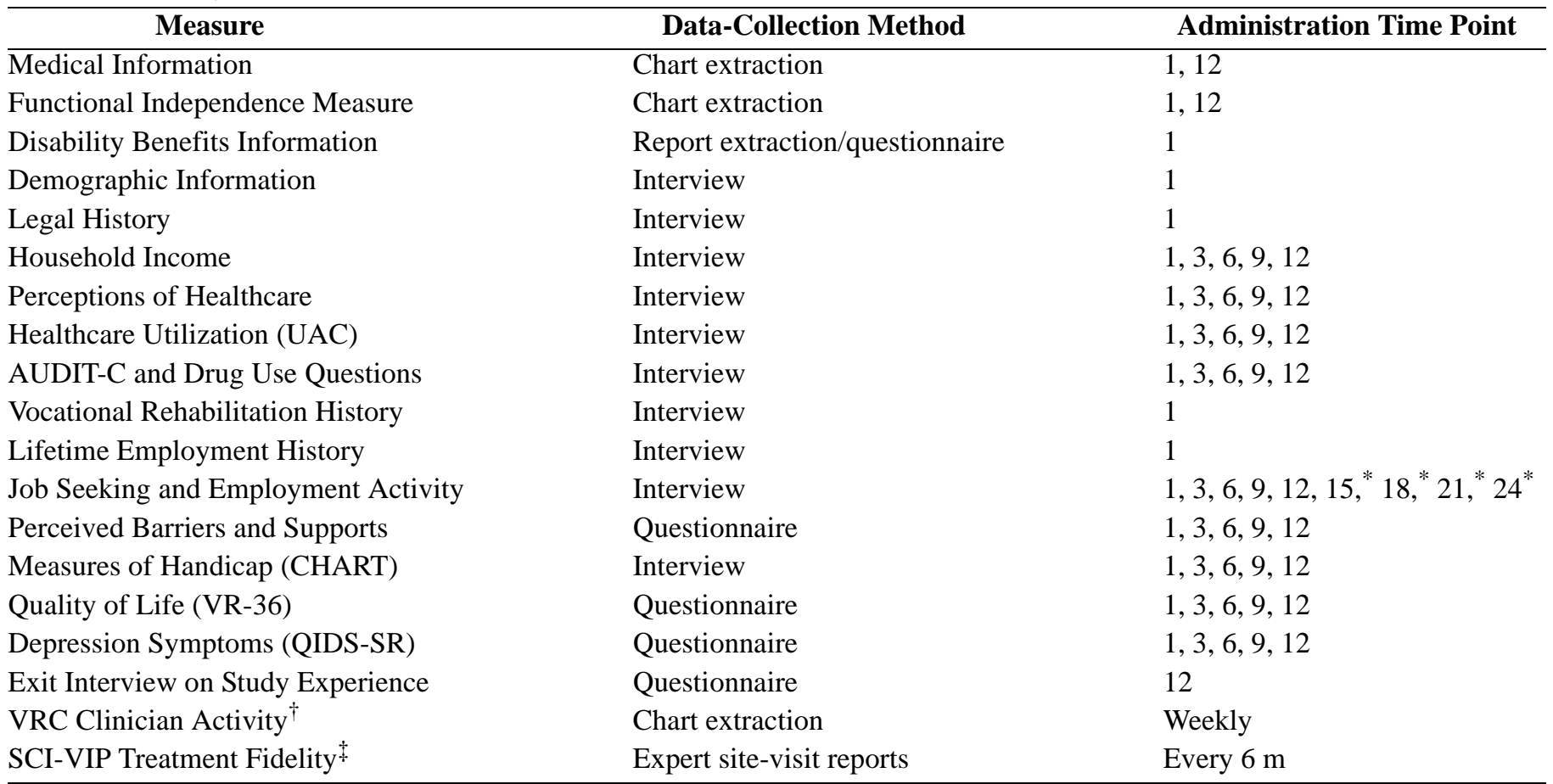

*Data collected on a subset of total participants.

${ }^{\dagger}$ Chart extraction for experimental condition only.

${ }^{\ddagger}$ Site visits conducted only at interventional study sites.

AUDIT-C = Alcohol Use Disorders Identification Test alcohol consumption questions, CHART $=$ Craig Handicap Assessment and Reporting Technique, QIDS-SR $=$ Quick Inventory of Depressive Symptomatology Self-Report, UAC = Utilization and Cost, VR-36 = Veterans RAND 36-Item Health Survey, VRC = vocational rehabilitation counselor. 
General rehabilitation outcomes are measured at baseline and 3-month follow-up intervals with the use of standardized measures, including:

1. The Alcohol Use Disorders Identification Test alcohol consumption questions measures alcohol use during the past 12 months [31-32]. Two investigator-developed questions about street-drug use and prescription drug misuse were added.

2. The Craig Handicap Assessment and Reporting Technique (CHART) assesses six dimensions of handicap identified by the World Health Organization: orientation, physical independence, mobility, occupation, social integration, and economic self-sufficiency [33]. The CHART has been successfully used to measure the societal impact of disability, or level of handicap, across several diagnostic groups [33-36].

3. The VR-36, an adaptation of the SF-36, measures healthrelated quality of life in the veteran population [33-40]. The VR-36 items contribute to eight domains: physical functioning, role-physical, bodily pain, general health, vitality, social functioning, role-emotional, and mental health. Physical and mental summary scales are also calculated [41].

4. The Quick Inventory of Depressive Symptomatology Self-Report measures symptoms of depression [42]. It has been found to be as sensitive over time in clinical trial outcomes as the longer self-report depression measures typically used in past research [43].

\section{Additional Data Sources}

Demographic variables such as age, sex, race/ethnicity, employment history, previous levels of income, educational background, legal history, lifetime employment history, vocational services history, duration of SCI, level of SCI, and type of family structure will be collected and used for analysis of differences between groups of subjects.

Benefits counseling information is collected that includes current amount and type of disability benefits as well as some limited qualitative information about the participants' experience of receiving benefits counseling during this study. Information is also collected regarding healthcare coverage status (Medicare, Medicaid, private health insurance, VA healthcare coverage). Data are collected on subjects' perceptions of vocational and medical treatment and perceptions of barriers and supports related to seeking employment.

\section{Fidelity Assessments}

Biannual fidelity assessments of the experimental condition to monitor and measure adherence to the evidence-based SE model are conducted with use of a modified version of the Supported Employment Fidelity Scale [13,44-45], formerly referred to as the Individual Placement and Support Fidelity Scale [44,46-47]. This scale contains 15 items that are rated on a 5-point scale from 1 (not implemented) to 5 (fully implemented) and yields a total fidelity score. During site visits, consultant trainers gather data on program fidelity through semistructured interviews with consumers, employers, clinicians, program managers, healthcare team members, administrative management and leadership; chart reviews; and observation of team meetings. The scale has been widely used and is consistently linked with employment outcomes among programs that serve persons with mental illness [23,48-49]. To our knowledge, this is the first time fidelity assessments have been performed with a population with physical disabilities.

\section{PRELIMINARY FINDINGS: ENROLLMENT TRENDS, STATUS, AND STRATEGIES}

Our final enrollment count is 301 subjects, of whom 63 (21\%) dropped out before the baseline interview. There were 238 baseline interviews completed, and to date, 93 subjects (39\%) have reached study completion. Our current attrition rate subsequent to the baseline interview is 14.7 percent. Recruitment challenges have included exhausting potential subject pools at some study sites earlier than expected, staff turnover, and the slow process of "culture change" within SCI Centers in terms of incorporating employment as a major goal in SCI rehabilitation and sustaining care. We addressed these challenges by replacing sites and/or treatment (observational vs interventional) conditions, increasing site coordinators from half time to full time, and continually working toward fully integrating SCI-VIP study staff into the SCI treatment teams and communicating a message that employment is a valid focus of healthcare treatment.

Our study sample consists of 95 percent males, and the average age is 48.2 years (standard deviation $=10.2$ ). On average, our sample has some college education (13.5 years of education) and 13.7 years have elapsed since their injury. More than half our subjects are white (50.4\%), followed by African American (35.3\%) and Hispanic (5.0\%). The types of SCIs experienced by our sample include paraplegia 
(50\%), high tetraplegia (32\%), and low tetraplegia (18\%). Baseline data indicate that 41 percent of this sample had previously received some type of vocational rehabilitation services and 35 percent reported they were able to obtain some kind of employment following their SCI, while 65 percent reported they were not.

\section{DISCUSSION}

This article described the methods of an ongoing randomized clinical trial of vocational rehabilitation approaches among veterans with SCI. This is the first study to apply evidence-based SE procedures to help veterans with SCI return to work. Strengths of the study design include the use of repeated measures to evaluate employment across time, the inclusion of benefits-counseling information, and ongoing fidelity monitoring of the treatment condition.

Implementing a field-based return-to-work experiment across multiple VAMCs is not without challenges. Before the study, our experience was that employment and vocational rehabilitation were not clinical priorities at the SCI centers because other more acute medical and rehabilitation needs took precedence. This lack of attention meant that both patients and providers were not accustomed to identifying or addressing vocational issues in the treatment setting. To effectively recruit patients who were willing to seek employment, we engaged in a cross-disciplinary educational process to elevate employment as a legitimate and valuable area of clinical focus. In effect, a culture change occurred such that providers began to introduce and explore the topic of employment and vocational goals in the outpatient clinic and inpatient unit and veterans who were willing to consider undertaking this significant life change were then referred to the project. Hence, recruitment in this study essentially relies on clinical providers' willingness to broaden their definition of rehabilitation to include vocational issues.

The primary limitation of this study will be the generalizability of our findings. At the time of enrollment, subjects could not be employed or employed part-time and earning above the Social Security Administration's determination of SGA. However, we should note that our preliminary baseline data from this ongoing trial indicate that the majority (72\%) of our sample of employment-seeking veterans with SCI had never been employed postinjury, a figure that is consistent with the low rates of employment found in community samples of persons with SCI [5051]. Another factor that may limit study generalizability is the fact that our sample largely consists of male veterans and, while this may be representative of the VA population with SCI, the experience of females with SCI may not be accurately represented by our study outcomes.

\section{CONCLUSIONS}

Identifying the rehabilitation methods that most effectively help veterans with serious physical disabilities reenter the workforce and resume productive civilian roles is of upmost importance; standard care has not been effective in this regard. The importance of work to quality of life and overall well-being cannot be overemphasized. Successful work participation will be expected to produce important psychosocial, economic, and health benefits for the person. Forthcoming outcome data will provide much-needed insights into the best practices for helping these veterans with SCI restore vocational goals and improve overall quality of life. This study will advance our understanding of both the real-world challenges and the benefits that need to be considered when evidence-based SE is applied to a population with serious physical impairments. The results of the CEA and the budget-impact analysis will assist administrators and policymakers in deciding whether to adopt this program. We hope that lessons learned from this model will one day be translated to other groups with serious and catastrophic disabilities such as brain injuries, burns, and amputations.

\section{ACKNOWLEDGMENTS}

\section{Author Contributions:}

Study concept and design: L. Ottomanelli, L. Goetz, C. McGeough, P. Sinnott, T. H. Wagner.

Analysis and interpretation of data: D. J. Cipher.

Drafting of manuscript: L. Ottomanelli, L. Goetz, J. Sippel, P. Sinnott, T. H. Wagner.

Critical revision of manuscript for important intellectual content:

L. Ottomanelli, L. Goetz, A. Suris, J. Sippel, P. Sinnott, T. H. Wagner, D. J. Cipher.

Statistical analysis: D. J. Cipher.

Study supervision: C. McGeough.

Financial Disclosures: The authors have declared that no competing interests exist.

Funding/Support: This material was based on work supported by VA Rehabilitation Research and Development Service (grant B3773R).

Additional Contributions: We acknowledge the overall leadership and support provided to the project by Margaret Hammond, MD, and Anthony Campinell, PhD. We thank Rich Toscano, MEd, who provided evidence-based SE training and conducted the fidelity ratings. We wish to thank the following participating investigators: Thomas Dixon, PhD; 
Christine Frick, PsyD; Kevin Gerhart, MD, PhD; Sally Anne Holmes, MD; Anthony J. Kerrigan, PhD; Robbie Logan, MD; Yvonne Lucero, MD; Angela Cass-Prost, PsyD; Paul Sandford, MD; and Florian Thomas, MD, MA, PhD. We also thank the program managers from CWT's Therapeutic Employment and Support Program: Sharon Crowder, LCSW; Heloise Ferguson, MSW, MPH; Thomas Halfhill, LISW; Teresa House-Hatfield, LMSW, LCSW, ACSW; Kerry Lynch, PhD; Marian Nalepa, LISW; Frederick Pecharka, MA, PC, CRC; and Rebecca Williams, PhD. We acknowledge the dedicated efforts of the local research coordinators and VRCs without whom this project would not be possible. This article benefited from the data-management assistance of Ledia Bradshaw, MPH, and the technical assistance of Megan Howard, MA. Finally, we wish to express our sincere appreciation for all the veterans who participate in this study with us.

Participant Follow-Up: The authors plan to inform participants of the publication of this study.

\section{REFERENCES}

1. Krause JS. The relationship between productivity and adjustment following spinal cord injury. Rehabil Couns Bull. 1990;33(3):188-99.

2. Trieschmann RB. The psychological, social, and vocational adjustment to spinal cord injury. Annu Rev Rehabil. 1980; 1:304-18. [PMID: 7186301]

3. Yerxa EJ, Baum S. Engagement in daily occupations and life satisfaction among people with spinal cord injuries. Occup Ther J Res. 1986;6(5):271-83.

4. Yasuda S, Wehman P, Targett P, Cifu DX, West M. Return to work after spinal cord injury: A review of recent research. NeuroRehabilitation. 2002;17(3):177-86. [PMID: 12237497]

5. Chapin MH, Kewman DG. Factors affecting employment following spinal cord injury: A qualitative study. Rehabil Psychol. 2001;46(4):400-16. DOI:10.1037/0090-5550.46.4.400

6. Krause JS. Longitudinal changes in adjustment after spinal cord injury: A 15-year study. Arch Phys Med Rehabil. 1992;73(6):564-68. [PMID: 1622306]

7. Westgren N, Levi R. Quality of life and traumatic spinal cord injury. Arch Phys Med Rehabil. 1998;79(11):1433-39.

[PMID: 9821906]

DOI:10.1016/S0003-9993(98)90240-4

8. Becker DR, Drake RE. Supported employment interventions are effective for people with severe mental illness. Evid Based Ment Health. 2006;9(1):22. [PMID: 16436562] DOI:10.1136/ebmh.9.1.22

9. Bond GR, Becker DR, Drake RE, Rapp CA, Meisler N, Lehman AF, Bell MD, Blyler CR. Implementing supported employment as an evidence-based practice. Psychiatr Serv. 2001;52(3):313-22. [PMID: 11239097]

DOI:10.1176/appi.ps.52.3.313
10. Bond GR. Supported employment: Evidence for an evidencebased practice. Psychiatr Rehabil J. 2004;27(4):345-59.

[PMID: 15222147]

DOI:10.2975/27.2004.345.359

11. Bond GR, Drake RE, Becker DR. An update on randomized controlled trials of evidence-based supported employment. Psychiatr Rehabil J. 2008;31(4):280-90. [PMID: 18407876] DOI:10.2975/31.4.2008.280.290

12. Resnick SG, Rosenheck R. Dissemination of supported employment in Department of Veterans Affairs. J Rehabil Res Dev. 2007;44(6):867-78. [PMID: 18075943] DOI:10.1682/JRRD.2007.02.0043

13. Bond GR, McHugo GJ, Becker DR, Rapp CA, Whitley R. Fidelity of supported employment: Lessons learned from the National Evidence-Based Practice Project. Psychiatr Rehabil J. 2008;31(4):300-305. [PMID: 18407879] DOI:10.2975/31.4.2008.300.305

14. Ottomanelli L, Goetz LL, McGeough C, Kashner TM. Building research capacity through partnerships: Spinal Cord Injury-Vocational Integration Program Implementations and Outcomes inaugural meeting. J Rehabil Res Dev. 2007;44(1):vii-xii. [PMID: 17551852]

DOI:10.1682/JRRD.2006.06.0072

15. United States Government Accountability Office. VA Vocational Rehabilitation and Employment: Better incentives, workforce planning, and performance reporting could improve program. Washington (DC): GAO; 2009 Jan. 44 p; Report No: GAO-09-34. Available from: http://www.gao.gov/new.items/d0934.pdf/.

16. Eisele JR. Biased coin designs: Some properties and applications. In: Flournoy N, Rosenberger WF, editors. Adaptive designs: Papers from the Joint AMS-IMS-SIAM Summer Conference held at Mt. Holyoke College, South Hadley, MA, July 1992. Hayward (CA): Institute of Mathematical Statistics; 1995. p. 48-64.

17. Stevens J. Applied multivariate statistics for the social sciences. 4th ed. Mahwah (NJ): Erlbaum; 2002.

18. Drummond M, Sculpher M. Common methodological flaws in economic evaluations. Med Care. 2005 Jul;43 (7 Suppl):5-14. [PMID: 16056003]

19. Gold MR, Siegel JE, Russell LB. Cost-effectiveness in health and medicine. New York (NY): Oxford University Press; 1996.

20. Brazier J, Usherwood T, Harper R, Thomas K. Deriving a preference-based single index from the UK SF-36 Health Survey. J Clin Epidemiol. 1998;51(11):1115-28.

[PMID: 9817129]

DOI:10.1016/S0895-4356(98)00103-6

21. Brazier J, Roberts J, Deverill M. The estimation of a preference-based measure of health from the SF-36. J Health Econ. 2002;21(2):271-92. [PMID: 11939242]

DOI:10.1016/S0167-6296(01)00130-8 
22. Phibbs CS, Luft HS. Correlation of travel time on roads versus straight line distance. Med Care Res Rev. 1995; 52(4):532-42. [PMID: 10153313] DOI:10.1177/107755879505200406

23. Becker DR, Xie H, McHugo GJ, Halliday J, Martinez RA. What predicts supported employment program outcomes? Community Ment Health J. 2006;42(3):303-13.

[PMID: 16532378] DOI:10.1007/s10597-006-9037-8

24. Cook JA, Leff HS, Blyler CR, Gold PB, Goldberg RW, Mueser KT, Toprac MG, McFarlane WR, Shafer MS, Blankertz LE, Dudek K, Razzano LA, Grey DD, BurkeMiller J. Results of a multisite randomized trial of supported employment interventions for individuals with severe mental illness. Arch Gen Psychiatry. 2005;62(5): 505-12. [PMID: 15867103]

DOI:10.1001/archpsyc.62.5.505

25. Burns T, Catty J, Becker T, Drake RE, Fioritti A, Knapp M, Lauber C, Rössler W, Tomov T, Van Busschbach J, White S, Wiersma D, EQOLISE Group. The effectiveness of supported employment for people with severe mental illness: A randomised controlled trial. Lancet. 2007;370(9593): 1146-52. [PMID: 17905167]

26. Go BK, Devivo MJ, Richards JS. The epidemiology of spinal cord injury. In: Stover SL, DeLissa JA, Whiteneck GG, editors. Spinal cord injury: Clinical outcomes from the model systems. Gaithersburg (MD): Aspen; 1995. p. 21-55.

27. Fuhrer MJ, Carter RE, Donovan WH, Rossi CD, Wilkerson MA. Postdischarge outcomes for ventilator-dependent quadriplegics. Arch Phys Med Rehabil. 1987;68(6):353-56. [PMID: 3592948]

28. Fuhrer MJ, Rintala DH, Hart KA, Clearman R, Young ME. Relationship of life satisfaction to impairment, disability, and handicap among persons with spinal cord injury living in the community. Arch Phys Med Rehabil. 1992;73(6): 552-57. [PMID: 1622304]

29. Grey N, Kennedy P. The Functional Independence Measure: A comparative study of clinician and self ratings. Paraplegia. 1993;31(7):457-61. [PMID: 8371936]

30. Hall KM, Cohen E, Wright J, Call M, Werner P. Characteristics of the Functional Independence Measure in traumatic spinal cord injury. Arch Phys Med Rehabil. 1999;80(11): 1471-76. [PMID: 10569443] DOI:10.1016/S0003-9993(99)90260-5

31. Bush K, Kivlahan DR, McDonell MB, Fihn SD, Bradley KA. The AUDIT alcohol consumption questions (AUDITC): An effective brief screening test for problem drinking. Arch Intern Med. 1998;158(16):1789-95. [PMID: 9738608] DOI:10.1001/archinte.158.16.1789

32. Rumpf HJ, Hapke U, Meyer C, John U. Screening for alcohol use disorders and at-risk drinking in the general population: Psychometric performance of three questionnaires.
Alcohol Alcohol. 2002;37(3):261-68. [PMID: 12003915]

DOI:10.1093/alcalc/37.3.261

33. Whiteneck GG, Charlifue S, Gerhart KA, Overholser D, Richardson GN. Guide for use of the CHART: Craig Handicap Assessment and Reporting Technique. Englewood (CO): Craig Hospital; 1992.

34. Whiteneck GG, Charlifue SW, Frankel HL, Fraser MH, Gardner BP, Gerhart KA, Krishnan KR, Menter RR, Nuseibeh I, Short DJ, Silver JR. Mortality, morbidity, and psychosocial outcomes of persons spinal cord injured more than 20 years ago. Paraplegia. 1992;30(9):617-30.

[PMID: 1408338]

35. Whiteneck GG, Charlifue SW, Gerhart KA, Overholser JD, Richardson GN. Quantifying handicap: A new measure of long-term rehabilitation outcomes. Arch Phys Med Rehabil. 1992;73(6):519-26. [PMID: 1622299]

36. Whiteneck GG. Evaluating outcome after spinal cord injury: What determines success? 1996 Donald Munro Lecture. J Spinal Cord Med. 1997;20(2):179-85. [PMID: 9144607]

37. Kazis LE, Ren XS, Lee A, Skinner K, Rogers W, Clark J, Miller DR. Health status in VA patients: Results from the Veterans Health Study. Am J Med Qual. 1999;14(1):28-38. [PMID: 10446661] DOI:10.1177/106286069901400105

38. Kazis LE, Clark J, Miller DR, Skinner K, Spiro A, Payne S, Linzer M, D’Agostino R, Lincoln E, Pierce C. A modified version of a short form health survey for assessing health related quality of life in veterans: The Veterans Health Study. Association for Health Services Research Meeting; 1994 Jun 12; San Diego, CA. Bedford (MA): Department of Veterans Affairs; 1994. p. 14-15.

39. Kazis LE, Skinner K, Rogers W, Wilson N. Health status of veterans: Physical and Mental Component Summary Scores (SF-12V): 1997 National survey of ambulatory care patients. Washington (DC): Department of Veterans Affairs, Veterans Health Administration Office of Performance and Quality; 1998.

40. Kazis LE, Miller DR, Clark JA, Skinner KM, Lee A, Ren XS, Spiro A 3rd, Rogers WH, Ware JE Jr. Improving the response choices on the Veterans SF-36 Health Survey Role Functioning scales: Results from the Veterans Health Study. J Ambul Care Manage. 2004;27(3):263-80. [PMID: 15287216]

41. Kazis LE, Skinner K, Rogers W. Health status and outcomes of veterans: Physical and mental component summary scores (SF-36V): 1998 National survey of ambulatory care patients: Mid-year executive report. Washington (DC): Department of Veterans Affairs, Veterans Health Administration Office of Performance and Quality; 1998.

42. Rush AJ, Trivedi MH, Ibrahim HM, Carmody TJ, Arnow B, Klein DN, Markowitz JC, Ninan PT, Kornstein S, Manber R, 
Thase ME, Kocsis JH, Keller MB. The 16-Item Quick Inventory of Depressive Symptomatology (QIDS), clinician rating (QIDS-C), and self-report (QIDS-SR): A psychometric evaluation in patients with chronic major depression. Biol Psychiatry. 2003;54(5):573-83.

[PMID: 12946886]

DOI:10.1016/S0006-3223(02)01866-8

Erratum in: Biol Psychiatry. 2003;54(5):585.

43. Rush AJ, Trivedi MH, Carmody TJ, Ibrahim HM, Markowitz JC, Keitner GI, Kornstein SG, Arnow B, Klein DN, Manber R, Dunner DL, Gelenberg AJ, Kocsis JH, Nemeroff CB, Fawcett J, Thase ME, Russell JM, Jody DN, Borian FE, Keller MB. Self-reported depressive symptom measures: Sensitivity to detecting change in a randomized, controlled trial of chronically depressed, nonpsychotic outpatients. Neuropsychopharmacology. 2005;30(2):405-16.

[PMID: 15578008]

DOI:10.1038/sj.npp.1300614

44. Bond GR, Becker DR, Drake RE, Vogler KM. A fidelity scale for the individual placement and support model of supported employment. Rehabil Couns Bull. 1997;40(4): 265-84.

45. Bond GR, Vogler KM, Resnik SG, Evans LJ, Drake RE, Becker D. Dimensions of supported employment: Factor structure of the IPS fidelity scale. J Ment Health. 2001; 10(4):383-93. DOI:10.1080/09638230120041146

46. Evans LJ, Bond GR. Expert ratings on the critical ingredients of supported employment for people with severe mental illness. Psychiatr Rehabil J. 2008;31(4):318-31.
[PMID: 18407882]

DOI:10.2975/31.4.2008.318.331

47. Supported employment implementation resource kit user's guide [Internet]. 2003. Available from:

http://download.ncadi.samhsa.gov/ken/pdf/toolkits/ employment/02.SE_Users.pdf/.

48. Becker DR, Smith J, Tanzman B, Drake RE, Tremblay T. Fidelity of supported employment programs and employment outcomes. Psychiatr Serv. 2001;52(6):834-36.

[PMID: 11376236]

DOI:10.1176/appi.ps.52.6.834

49. Bond GR, Salyers MP. Prediction of outcome from the Dartmouth assertive community treatment fidelity scale. CNS Spectr. 2004;9(12):937-42. [PMID: 15616478]

50. Krause JS, Anson CA. Employment after spinal cord injury: Relation to selected participant characteristics. Arch Phys Med Rehabil. 1996;77(8):737-43. [PMID: 8702365] DOI:10.1016/S0003-9993(96)90250-6

51. Krause JS, Kewman D, DeVivo MJ, Maynard F, Coker J, Roach MJ, Ducharme S. Employment after spinal cord injury: An analysis of cases from the Model Spinal Cord Injury Systems. Arch Phys Med Rehabil. 1999;80(11): 1492-1500. [PMID: 10569446] DOI:10.1016/S0003-9993(99)90263-0

Submitted for publication October 30, 2008. Accepted in revised form April 21, 2009. 